\title{
Redesign Solid Waste Collection and Transference System for Addis Ababa (Ethiopia) Based on the Comparison with Shanghai, China
}

\author{
Diriba Dechasa Beka1, Xiang-Zhou Meng1,2* \\ ${ }^{1}$ College of Environmental Science and Engineering, UNEP-TONGJI Institute of Environment for Sustainable Development, \\ Tongji University, Shanghai, China \\ ${ }^{2}$ State Key Laboratory of Pollution Control and Resources Reuse, College of Environmental Science and Engineering, \\ Tongji University, Shanghai, China \\ Email: *xzmeng@tongji.edu.cn, dechasabeka1@gmail.com
}

How to cite this paper: Beka, D.D. and Meng, X.-Z. (2021) Redesign Solid Waste Collection and Transference System for Addis Ababa (Ethiopia) Based on the Comparison with Shanghai, China. Open Access Library Journal, 8: e7470.

https://doi.org/10.4236/oalib.1107470

Received: April 28, 2021

Accepted: May 15, 2021

Published: May 18, 2021

Copyright () 2021 by author(s) and Open Access Library Inc.

This work is licensed under the Creative Commons Attribution International License (CC BY 4.0).

http://creativecommons.org/licenses/by/4.0/

\begin{abstract}
Solid waste, that is produced as a result of human activity on a daily basis, must be properly managed. Like other cities in developing nations, Addis Ababa is facing problems linked to poorly managing solid waste gathering operations. This study analyzed the existing public solid waste gathering system in the city and undertook a comparative analysis with Shanghai's solid waste collection system. Qualitative and quantitative data were collected through surveys as well as secondary sources and then comparative analysis with Shanghai has been undertaken. According to the investigation of this research, solid waste collection coverage of Addis Ababa is $70 \%$ and only $28.6 \%$ of households have separate solid waste at source. Besides, according to respondents, $75.3 \%$ of residents were using a sack to collect the waste and only $14.5 \%$ were using the waste bin. The study found that lack of access of infrastructures, a lack of an adequately built collection route system and schedule, inadequate and faulty facilities for operations, and corner littering around skips that resulted in improper disposal are among the causes of poor efficiency of solid waste handling in the metropolitan. Lack of understanding, improper disposal, the poor status of waste collectors, the absence of the private sector, and public engagement are some of the social issues that have been experienced. The main problem with the incompetence of this sector in the city was the lack of trained labor and inadequate service delivery. In conclusion, based on Shanghai City's best practices, the research applied about useful suggestions for strengthening the system and re-designing it.
\end{abstract}




\section{Subject Areas}

Environmental Sciences

\section{Keywords}

Redesign, Waste Collection, Re-Use, Addis Ababa

\section{Introduction}

The worldwide population has been growing rapidly, especially in developing nations [1]. Such rapid growth of population, together with the economic boom and rising and shifting of community living standards has led to an increasing municipal solid waste creation rate [1] [2]. Most countries are experiencing growing pressure on energy, the atmosphere, and biodiversity as a result of global climate change and economic growth. Pollution of water and solid waste is becoming increasingly severe [3]. Solid waste is something that isn't liquid or gas and is discharged as undesirable, and its management includes storing, processing, transporting, reuse, removal, or the potential use of a decommissioned dumping site [4] [5]. Waste material, that is produced as a result of human activity on a daily basis, must be properly managed. Municipal solid waste management has become a worldwide challenge [6]. For middle- and lower-income countries, its administration is more complicated [7].

In urban areas, the solid waste composition is more complex and heterogeneous [8]. In most emerging cities, the produced solid waste is not handled properly concerning storage, collection, transportation, and final disposal and leads to serious issues. The basic method of urban garbage management refers to [9] collecting solid waste from the residence, commercial, and public areas and then conveys it to the landfill. A weak municipal dry waste gathering system could lead to the atmosphere, water, and soil pollution, and risk to public health [10]. Due to the lack of expertise, capacity, and willingness, the collection phase is described as a key issue. In developing nations, garbage collection services reach up to $50 \%$ [11].

Municipal solid waste handling cost accounts for $20 \%$ - $50 \%$ of the government financial plan with $80 \%-90 \%$ of that spending on waste collection [12]. However, less than $50 \%$ of the population obtains the services [13] [14]. It is very difficult to sustain the solid waste gathering system by government budgets [15], and local authorities have started to cooperate with the private sector [16] [17]. Besides, municipal solid waste management (MSWM) is strongly influenced by socio-cultural, environmental, political, legal, and economic factors that need to be all addressed to realize a sustainable MSWM [18]. However, only careful management will reduce and control the harm done to the ecology and conserve limited resources [19].

Addis Ababa has one of Africa's fastest-growing populations. Since its establishment 100 years ago, the population has increased from 15,000 to 4.59 million 
[7]. Enlarged expansion and increasing of the population in Addis Ababa, combined with a deficiency of resources to deliver basic facilities and urban services, have led to a series of difficulties such as the increased generation of waste and inadequate gathering, conveyance, and dumping of solid waste. This has become the main threat to the urban environment and the well-being of the citizens in Addis Ababa [20]. Despite this accelerated pace of solid waste production waste collection rates are lesser than $70 \%$ in un-industrialized countries. In the same way, in Addis Ababa, the competence of the city's collection and transportation of solid waste, and dumping system remains poor. More than $50 \%$ of the leftover gathered is regularly discarded by unregulated open landfilling, while $15 \%$ in Addis Ababa is managed by insecure and informal recycling [21].

Insufficient city dry waste collection and conveyance system may have significant adverse ecological influences, such as transmittable diseases, contamination of land and water, sanitation barriers, and harm to human health. Its environmental fears including pollution of groundwater and shallow water by leachate, and air pollution from burning of waste that is not appropriately collected and disposed of [22]. There are gaps between what is needed and what is on the ground. The general objective of the research is to redesign the solid waste collection and transference system for Addis Ababa city based on the best practice of Shanghai.

Therefore, this research was interested by the need to fill the above gaps in knowledge by identifying the gaps of the current public solid waste collection services in Addis Ababa and redesigned an appropriate system based on the comparison with Shanghai.

\section{Research Design and Methodology}

\subsection{Background Information on the City of Addis Ababa}

Addis Ababa city was founded during Menelik II in 1886. Since then it is the capital and the largest city in the country. Addis Ababa, the capital city of Ethiopia, is located between $8^{\circ} 55^{\prime} \mathrm{N}$ and $9^{\circ} 05^{\prime} \mathrm{N}$ Latitude and $38^{\circ} 40^{\prime} \mathrm{E}$ and $38^{\circ} 50^{\prime} \mathrm{E}$ Longitude. The city is located at the center of Ethiopia in an area of $540 \mathrm{~km}^{2}$ of which 18.174 $\mathrm{km}^{2}$ is rural and its altitude ranges from $2000-2800$ meters above sea level. It is bordered by Oromia Regional State in all directions. There are 10 sub-cities and about 119 districts. Its annual average temperature is between $10^{\circ} \mathrm{C}$ to $24^{\circ} \mathrm{C}$ and the average yearly precipitation is $1200 \mathrm{~mm}$ [23]. Infrastructure facilities are found in a better situation than other Ethiopian cities since they are focused on modern economic, political, and social activities. The city currently has a population of $4,592,000$ (CSA, 2019) out of the total population of the nation which is more than 100 million right now. The city's population growth rate, which is about $4.36 \%$ annually, is due to both birth and migration (Figure 1).

\subsection{Background Information on the City of Shanghai}

Shanghai is situated at $31^{\circ} 14^{\prime}$ north latitude and $121^{\circ} 29^{\prime}$ east longitude, on the 


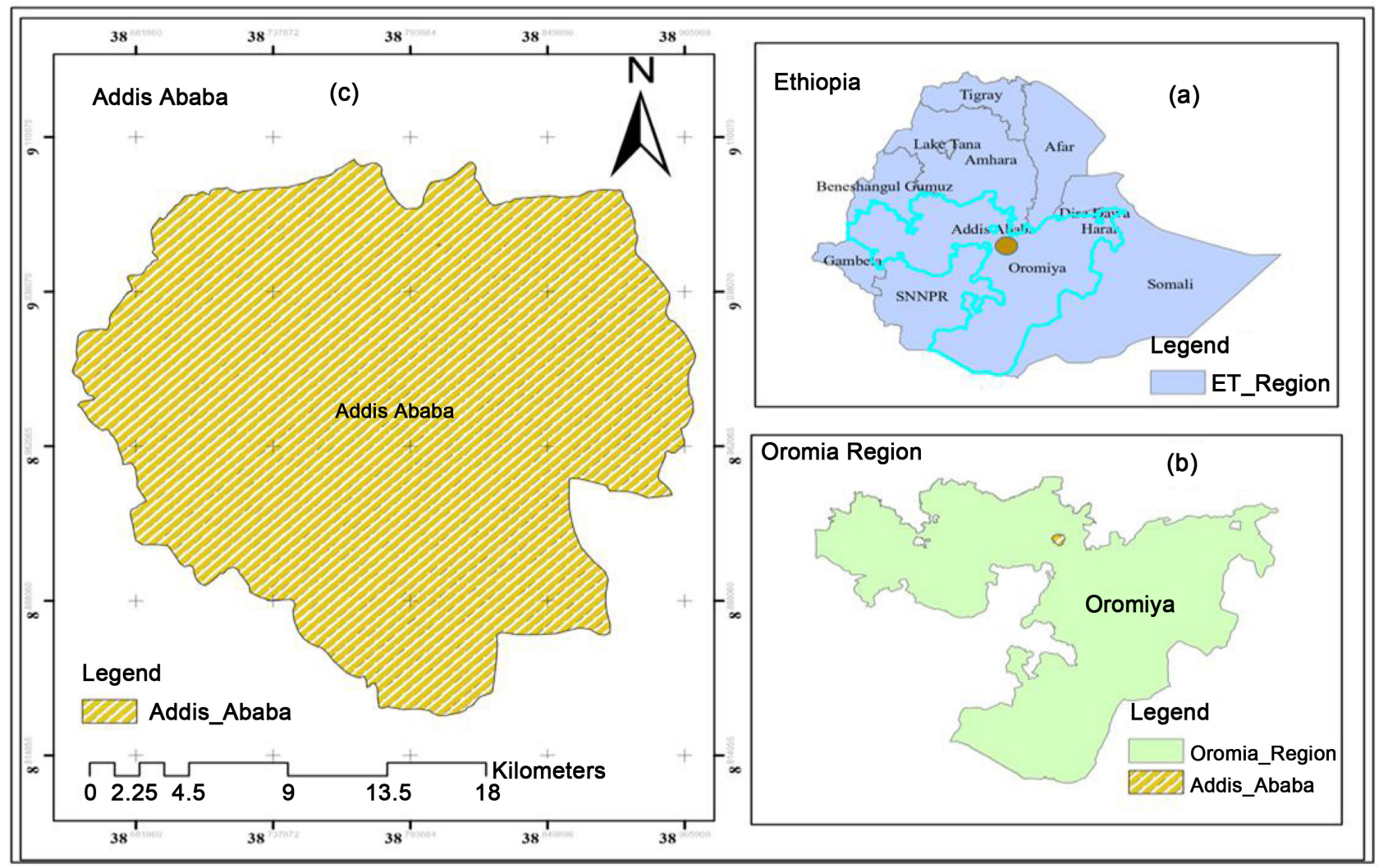

Figure 1. Location map: (a) Ethiopia, (b) Oromia region, (c) Addis Ababa. Source: Developed using ArcGIS.

west coast of the Pacific Ocean, with the Asian continent's eastern coastal line and part of the Yangtze River Delta's alluvial plain preserved. To the west, Shanghai borders the provinces of Jiangsu and Zhejiang. The Yangtze River empties into the East China Sea north of the city. The average height above sea level is 2.19 meters. Its annual average temperature is $17.7^{\circ} \mathrm{C}$ and its annual average precipitation is $1407.9 \mathrm{~mm}$. The city has a total area of $6340.5 \mathrm{~km}^{2}$ and is divided into 16 districts, 107 sub-district committees, 106 villages, and two townships as of the end of 2019. In 2019, Shanghai had a population of 24.2814 million inhabitants, with an average life expectancy of 83.66 years (Information office of Shanghai municipality, Shanghai municipal statistics bureau, 2020).

\subsection{Research Approach}

The fundamental idea of this research methodology is to develop (Redesign) a collection system for the city of Addis Ababa based on the comparison with Shanghai. The analysis ranges from the identification of waste generators, amount of waste created and waste compositions, gap identification, waste collection and conveyance practices, policy options, and intervention strategies that enhance the sustainability of waste collection and transference system. To achieve the research objectives, data from national, city administration, sub-city, and community levels of society were gathered through qualitative and quantitative research methods and then comparative analysis with Shanghai's waste collection system 
has been undertaken.

\subsection{Data Sources}

In this study, all of the required data was gathered from both primary and secondary sources. To minimize the non-response rate and data incompleteness, the study used primary data sources from sample households through a standardized questionnaire and face-to-face interviews with state officials from various sectors and solid waste collector cooperatives. Secondary data was gathered from a variety of sources, both known and unpublished.

\subsection{Sampling Techniques and Sample Size}

The study area was chosen by the researcher with the help of officials from the city municipality office. The sample size has beeen determined based on the sample's representativeness and resource constraints. To create the sampling frame, woredas administration offices created a list of residents. The primary data sources for this analysis are sample households. The sampling frame population was made up of 410 households from the 12,850 households in three sample woredas, which were proportionally distributed for each sample woreda (Table 1). The residents were then chosen at random to ensure the study's representativeness. The Krejcie and Morgan method for determining sample size in study is commonly used. The following formula was used by Krejcie and Morgan (1970) to determine sample size.

$$
S=X^{2} N P(1-P) / d^{2}(N-1)+X^{2} P(1-P)
$$

$S$ is equals to required sample size

$X^{2}=$ the table value of chi-square for one degree of freedom at the desired confidence level (3.841)

$N=$ the population size

$P=$ the population proportion (assumed to be 0.50 since this would provide the maximum sample size)

$d=$ the degree of accuracy expressed as a proportion (0.05).

The requisite sample size is calculated using the formula above:

$$
\begin{aligned}
S & =3.841 \times 12850 \times 0.50(1-0.5) /(0.05)^{2}(12850-1)+3.841 \times 0.50(1-0.50) \\
& =12339.21 / 33.08275=373
\end{aligned}
$$

Table 1. Summary of a household sample size from each woreda.

\begin{tabular}{cccc}
\hline No & Selected sample Woreda & Population size (N) & $\begin{array}{c}\text { The sample size of } \\
\text { each Woreda (S) }\end{array}$ \\
\hline 1 & Woreda 03 & 4550 & 145 \\
2 & Woreda 05 & 3600 & 115 \\
3 & Woreda 08 & 4700 & 150 \\
& Total & 12,850 & 410 \\
\hline
\end{tabular}


As a result, the minimum sample size of households for accurate findings was 373. However, assuming a $10 \%$ non-response rate, the sample size would be 410 people. Finally, the researcher chose to survey households from various woredas using the proportional distribution method as shown below (Table 1).

The researcher has developed two survey instruments to gather the necessary data from households and experts (i.e. questionnaire and checklist). The checklist's main objective was to provide a general overview of the city's current solid waste collection system and to assist in the detection of garbage collection issues. After a pre-test, the questionnaire was finalized. This survey was conducted from September to October 2020.

\subsection{Data Analysis Methods}

This research has been used in a combination of approaches for quantitative and qualitative data collection. A questionnaire, observation, and interview were used to gather primary data. After that, secondary data was collected from the internet, government reports, and journal articles. All of the collected data from the sources was analyzed using basic descriptive statistics, including both qualitative and quantitative methods. Percentages, interactive maps, and tabular structure are examples of quantitative approaches.

Qualitative methods have also been used to interpret data obtained by direct physical observation or visualization by explaining the phenomenon using personal judgement and accompanied by photographs. Then, the data have been exported into software (SPSS V.25.0) for analysis. Data also obtained from observation and interviews are used during analysis. Comparative analysis of the solid waste collection and transference system for Addis Ababa and Shanghai has been undertaken. The study provides a critical analysis of the data collected to justify the approaches that have been employed to arrive at new knowledge and remained valid and reliable.

\section{Results and Discussions}

\subsection{Demographic Characteristics of Sample Household}

The minimum sample size calculated for this research was 410 . However, the number of residents from each household that responded to the questionnaire was 385 . This makes the response rate of $94 \%$. The distribution of the residents in terms of social background regarding the sex of the residents who involved in the study comprised 225 females who account for $58.4 \%$ and 160 males who are $41.6 \%$.

Regarding the age of the residents who are involved in the study 132 (34.3\%) were at the age range of $30-39,127$ (33.0\%) were 20 - 29 years' age, 48 (12.5\%) were at the age range of $40-49,60$ years and above were 25 (6.5\%), below 20 years old $34(8.8 \%)$ and the remaining 50 - 59 years were $19(4.9 \%)$.

\subsection{Solid Waste Generation Rate in Addis Ababa}

According to the rapid population and economic growth, undesirable urban 
planning policy, management of municipal solid waste is a significant challenge for local administrations since wastes are generated from daily life activities in massive amounts, which are uncontrolled, and the trend is to increase with time [24]. As the city continued to grow in its population, the amount and types of wastes increase. The per capita waste shows an increasing trend.

According to the research done by [25], the per capita/kg/day solid waste generation of the city was $0.252 \mathrm{~kg}$ (As 2010). The quantity and quality of waste generated from households vary due to an increase in the living standard of the citizens, increasing the consumption of industrial products, a growth in the urbanization projects, establishment of urban agriculture, and the increasing population. There is a continuous and increasing volume of solid waste generation in the future [26] [27].

The key assumption is that waste generation increases mainly as a result of two factors: GDP growth and population growth. As a country's economy develops, so does its per capita waste generation rate. GDP per capita, adjusted for buying power, is used to measure economic growth. As a country's population increases, so does the amount of total waste generated. Daily municipal solid waste generation per capita worldwide in 2018 , by selected counties is depicted below (Figure 2).

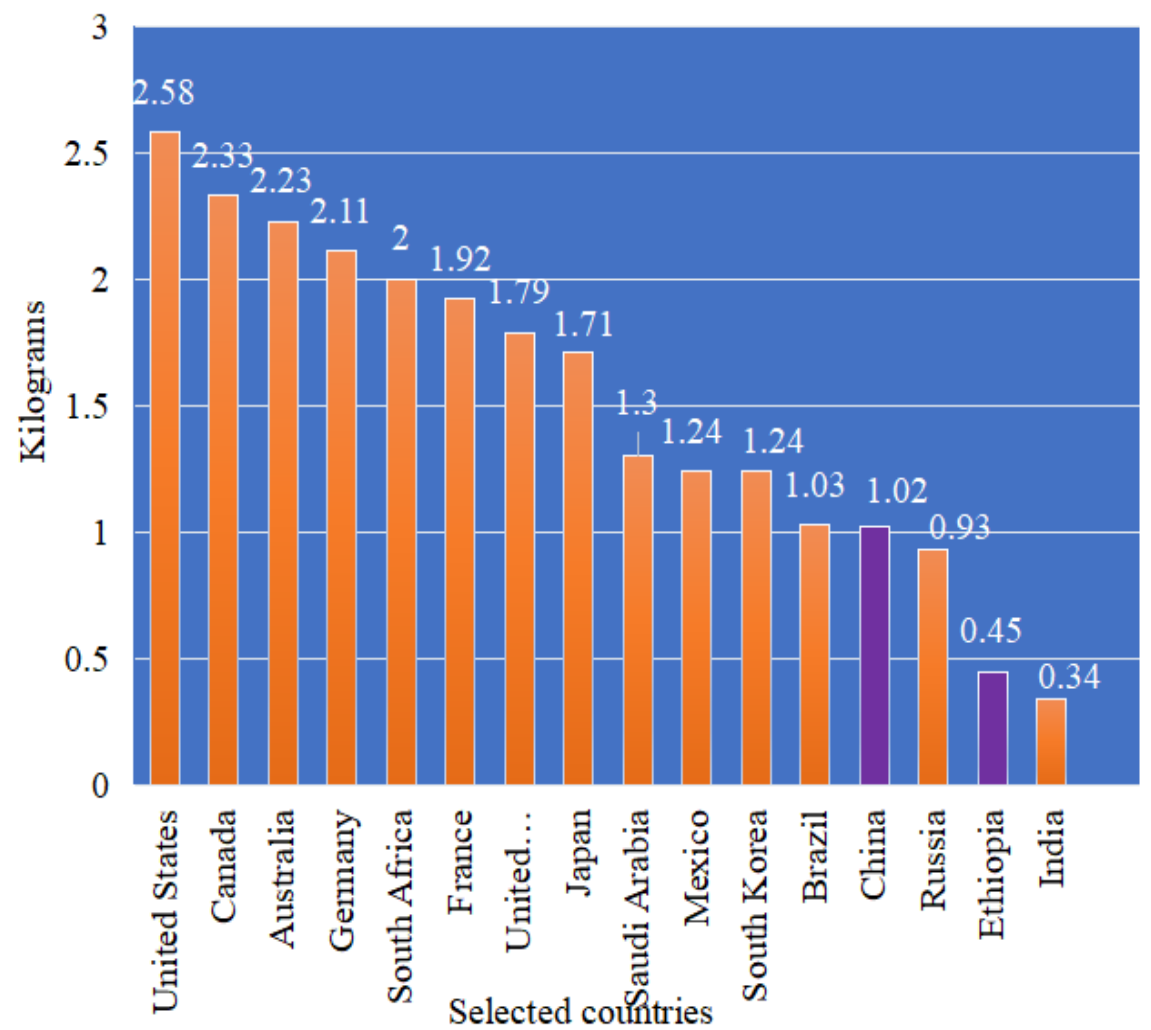

Figure 2. Daily municipal solid waste generation per capita worldwide in 2018 , by selected countries (in kilograms). Source:

https://www.statista.com/statistics/689809/per-capital-msw-generation-by-country-world wide/ (Accessed online January 10, 2021). 
Studies reveal that municipal garbage has increased from time to time. Currently, the public solid waste generation is assumed to be 1.3 billion tons of garbage and it will be 2.2 billion tonnes in 2025 worldwide [28]. The recent rise in the production of various kinds of waste in different quantities and qualities is due to industrialization [29]. In addition to this, technological advancements and rapid population growth have resulted in higher levels of consumption and household waste generation [30]. As a result, crises such as water and soil contamination, greenhouse gas emissions, and negative effects on human life quality could arise [31].

In Addis Ababa, each person's solid waste generation amount is $0.45 \mathrm{~kg}$ per person per day and as a total, more than 754,236 tonnes per year was obtained. There is a $5 \%$ increase in urban waste production per year [32]. Because of this enormous creation of solid waste, city residents considered urban dry waste handling as an essential and vital urban service. In Addis Ababa, insufficient urban and industrial solid waste collection and disposal causes a slew of environmental issues [32]. A large amount of garbage dumped in open garbage dumps or drainage systems, endangering the health of both surface and groundwater and causing flooding, which provides a breeding ground for disease-carrying pests. Air pollution is caused by waste burning in open air and indiscriminate burning in landfills.

In slums, where households do not have access to garbage collection sites, the situation is exacerbated. The lack of even the most basic solid waste facilities in densely populated and low-income neighborhoods is the primary cause of high morbidity and mortality among the urban poor [33]. This increase in waste makes public garbage collection challenging. Therefore, if the government pays proper attention to it and allocates a sufficient budget, it could be manageable and creates a conducive environment for the community.

\subsection{Sources of Solid Waste in Addis Ababa}

According to the study by [34], a large amount of waste is created in Addis Ababa city from several sources. The city is now facing a huge and complex problem with waste management. The waste management challenges emerge from an ever-increasing population of the city, which, in turn, aggravated the unbalanced waste collection service. The low prioritizing of the sector by the administrative body of the government is manifested in the allocation of low financing and the increasing volume and composition of waste created in the city.

There are various categories of solid wastes generated from institutions, households, hospitals, industries, street sweeping, etc. The types and volume of waste generated are diverse this is due to several reasons. Economic growth (Income), living standard, climate, consumption patterns, social and cultural backgrounds are the major factors. This indicates that as the living standard improves the amount and type of solid waste created increase and become diverse and complex. 
Domestic solid wastes are wide variations generated from household actions such as food preparation and feeding, garden wastes sweeping, burning, and used objects like clothing, furnishings, and abandoned apparatus. Domestic solid waste mentions to wastes created from housing areas from day to day actions called "household" solid wastes [21]. These types of wastes in lower-income countries like Ethiopia nourishment and residue wastes are dominated largely and account for the uppermost amount of municipal solid wastes. Households, roads, hospitals, factories, and commercial centers are the primary sources of solid waste in Addis Ababa. The households account for $76 \%$ of the total solid wastes generated (Figure 3).

According to the discovery of this research, the highest percentage of the source of solid waste in Addis Ababa is households. Therefore, intensive education to raise the awareness and attitude of the households has a significant impact on the garbage collection service of Addis Ababa.

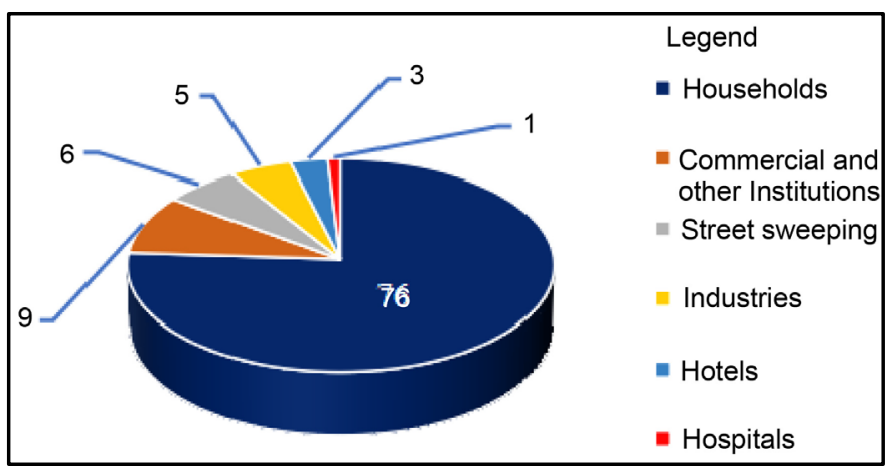

Figure 3. Source of solid waste generation by sector and its percentage in Addis Ababa. Source: Addis Ababa cleansing management agency (2017).

\subsection{Waste Composition}

As it is observed in studies that there is an increasing trend in solid waste generation due to population growth and urbanization. Urbanization brings a change in the lifestyle of the population and an increase in the volume and composition of waste. The composition of domestic waste is the prime consideration before collection and considering any process for its disposal or combustion or recycling [35]. In Addis Ababa, the physical composition of solid waste is organic $60 \%$, recyclable $15 \%$, and others $25 \%$ [36]. Most of the residents in this study reported that they generate organic waste $242(63 \%)$, paper and cardboards 52 (13.5\%), plastics $42(10.8 \%)$, Fruits and vegetables $16(4.2 \%)$, textile $10(2.6 \%)$, wood $9(2.3 \%)$, glasses $4(1 \%)$ and others such as ceramics, bones, earthenware, furniture, metal 10 (2.6\%) (Figure 4).

Cheru, (2016) [7] also stated that the physical composition of solid waste created in Addis Ababa city varies seasonally. Nevertheless, the large percentage of the waste is compostable, $47 \%$ ashes, leaves $15.7 \%, 4.2 \%$ vegetables, and the remaining wastes that can be recycled such as plastics $2.9 \%$, paper $2.5 \%$, metal 


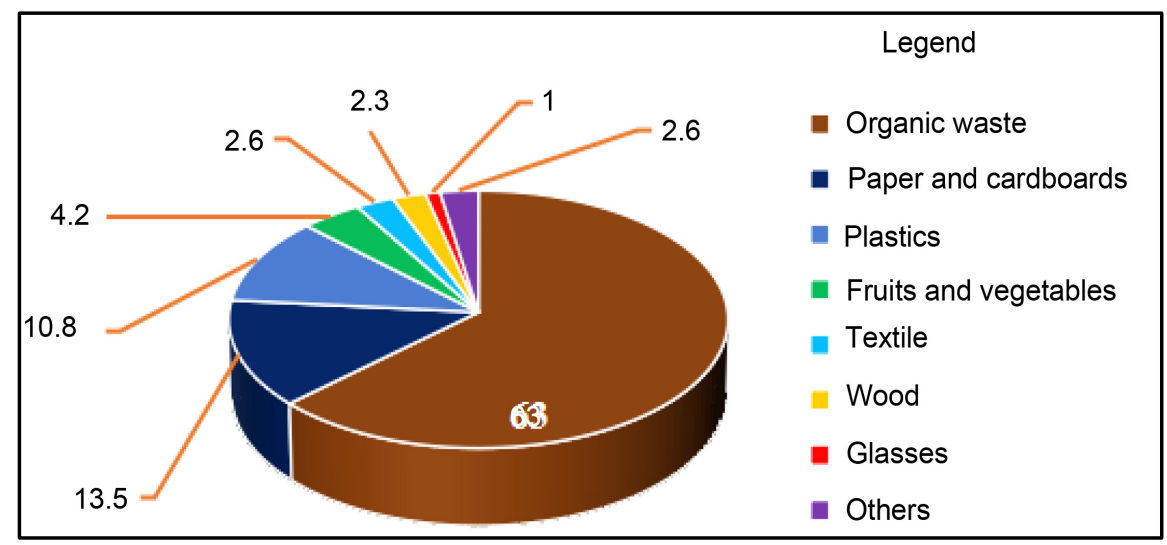

Figure 4. Composition of solid waste generated by households its percentage in Addis Ababa. Source: Field survey (September 2020).

$0.9 \%$, and glasses $0.5 \%$. Based on these research findings, no matter how varied the results, organic waste has the highest proportion in the composition. In addition, according to various studies, the highest percentage of municipal solid waste in developing nations is organic waste. The reason for this is thought to be the consumption pattern and living condition of the community. This trend indicates that the majority of waste created by households may be used to manufacture compost, biogas, and other types of waste that can be recycled.

\subsection{Factors that Influence Solid Waste Collection Service in Addis Ababa}

The current population of Ethiopia exceeds 100 million and it is expected to be more than 125 million in the year 2025 [37]. This makes the country one of the most populous nations in Africa next to Nigeria. This shows that the population explosion brings an increase in urbanization. As it is observed in studies that there is an increasing trend in solid waste generation due to population growth and urbanization [28] [38]. Urbanization brings a change in the lifestyle of the population and rise in the amount and composition of waste. This is manifested in Addis Ababa city.

Addis Ababa city's garbage collection service has crippled due to financial resources scarcity, lack of institutional capacity, lack of sufficient infrastructures, and absence of cooperation among various stakeholders. This in turn has made it difficult to render the basic solid waste gathering facility to the community.

The other challenge is related to the waste collection trucks, which are old and they can stop for several technical problems. Moreover, the lack of containers and spaces to place the container, and lack of institutional capacity to conduct timely supervision are the challenges mentioned in the interview.

\subsubsection{Waste Collection, Storage, and Transference Systems}

The method of collecting waste from its source, transporting it to nearby public solid waste containers or transfer stations, and eventually dumping it at a landfill site is known as collection and transference of solid waste [39]. This practical 
component is a very important and required part of municipal garbage management because it determines the output and efficiency of the service.

Addis Ababa municipal had started its solid waste service some six decades back, however, now the provision cannot meet the shifting demands. The community waste collection facility is insufficient, and scenes of distributed waste are common in most of the city [40]. According to the present policy, the administration workers, private companies based on prescribed agreements, and Micro and Small Enterprise (MSE), collect solid wastes. However, the principle, affirming that the waste creators are subject to put their wastes into different containers based on the exact type of wastes, is not experienced in the city [41].

The (2010) estimate of the United Nations (UN) indicated that only $65 \%$ of the solid waste created in the city is properly collected and dumped, while the remaining $35 \%$ of the waste being discarded improperly in open spaces, drainage systems, streets, and rivers.

Regarding solid waste storage, the researches were done by [42] [43] revealed that in Addis Ababa city garbage management, different types of containers are used to primarily store wastes in the households. These storing containers are not standardized such as sack, card boxes, cans, bamboo containers, baskets, and plastic bags. The households in the study area also stated that they store the solid waste $290(75.3 \%)$ used sacks as primary storage, 56 (14.5\%) used dustbins, 34 (8.8\%) threw the waste in a corner area while those $5(1.3 \%)$ disposed the waste straight to the storage.

The reason that the households dispose of solid wastes improperly may be due to shortage of awareness on how to dispose of wastes, insufficient waste collection facilities, carelessness, absence of proper legal control, and enforcement. This implies that standardized waste container is necessary to safeguard the proper storage and transportation of the waste; the need to raise the communal awareness on the problems created by environmental and personal health.

\subsubsection{Accessibility to Solid Waste Collection}

The distance of the containers from the residential area is also another factor that affects the efficiency of solid waste collection. The existing distance of the transfer station or containers from households is $0.5 \mathrm{~km}$ to $1 \mathrm{~km}$ far away in Addis Ababa, while the recommended standard is $150 \mathrm{~m}$ [25]. In unintended settlements such as shantytowns or low-income areas, this is extremely important and thus affects the choice of equipment.

As respondents reported in the study, the containers are placed with a distance of $0.5 \mathrm{~km} 153$ (39.7\%), $86(22.3 \%)$ with a distance of $0.5-1 \mathrm{~km}, 10(2.6 \%)$ more than $1 \mathrm{~km}$, and no containers at all are $138(35.8 \%)$. According to the investigation of this survey, $35.8 \%$ of the respondents have no waste disposal containers at all. This is one of the serious difficulties and obstacles for the effective solid waste collection provision in Addis Ababa city.

The secondary solid waste collection or transportation time interval of the containers from the transfer station to the final discarding site is discussed as 
follows. According to the respondent's response is collected weekly 268 (69.6\%), every two weeks 64 (16.6\%), and more than two weeks 53 (13.8\%). From this, we can understand that the time interval of the collection is very long and it is causing environmental pollution and health problems for the community. It indicates that a weak service delivery system of the solid waste management agency.

Researches indicate that as much as $60 \%$ of solid wastes in a low-income country are collected [44] [45]. The same is true for Addis Ababa city where 30\% (620 tons/day) of the solid waste left uncollected. The remaining solid wastes are discarded in the drainage, burned, or buried. The informal/throwing of solid wastes in this way is due to the shortage of availability of containers, and the timely transportation of the containers. This indicates that the agency's waste collection and transference management system has weaknesses, a fewer number of trucks, and a lack of supervision.

According to the interview from the city's health office, an insufficient city garbage collection services may have significant negative environmental impacts, such as infectious diseases, sanitation barriers, and harm to human health. Its environmental fears include pollution of groundwater and shallow water by leachate and air pollution from the burning of waste that is not appropriately collected and disposed of.

\subsubsection{Awareness and Attitudes}

Mismanagement by humans and sometimes short-sighted economic policies by national governments have had a tremendous negative effect on biodiversity and the natural environment around the world. Some scientists believe that the solution to this problem may lie in a thorough analysis and understanding of human environmental awareness and attitudes [46]. Public awareness and outlooks to waste can influence the whole solid waste handling system [47]. All aspects of waste management, from domestic waste separation to waste storage and reuse, collection frequency, scattering quantity, willingness to pay for waste management facilities, and opposition to the location of waste handling and dumping facilities, rely on public awareness and participation [48].

According to [42], as much as $80 \%$ of the solid waste created in the households are not separated by the residents in Addis Ababa. This waste is not much of it taken to recycling firms and reused. But there are fewer households that separate wastes as organic and inorganic [49]. The household trend in solid waste separation in Addis Ababa is not as much as needed. Those who are separating waste are for selling, reusing, or recycling [50].

The economic value of waste can increase if waste is segregated at the source, stored in separate storage materials, and collected in day-to-day activities. In this study, findings reveal that 110 (28.6\%) of the respondents replied that users have stored their waste with separation whereas the remaining 275 (71.4\%) of the respondents confirmed that they do not separate solid waste in to biodegradable and non-biodegradable. The respondents who separated wastes account for plas- 
tic (34.5\%), organic (39.7\%). The reason behind this is that they sell plastics, scrap metal, and use it as a source of income. However, the awareness of the society regarding environmental impact and solid waste separation according to its nature is very low. In addition to this, there is no policy to show the classification of solid waste in Addis Ababa, which is the pre-condition for the separation and all treatment system.

\section{Comparative Analysis of Municipal Solid Waste Collection Systems in Addis Ababa, Ethiopia, and Shanghai, China}

This section of the comparative analysis tries to examine the different elements of MSW collection in Addis Ababa, Ethiopia, and Shanghai, China, as well as discuss potential lessons that can be learned from Shanghai's MSW collection system to aid the development of an integrated waste collection system in Addis Ababa. Section 2 (description of the study area) provides background information on the two cities to help readers better understand their characteristics. To allow for comparisons between waste collection systems in the two cities, established waste collection systems are defined in terms of waste generation, waste composition, waste collection methods, and service coverage. Information from questionnaires, interviews, and reports for Addis Ababa, as well as published articles and documents obtained from the city authorities' official websites for Shanghai, was used to explain the waste collection systems. The solid waste collection schemes in Addis Ababa and Shanghai are then compared in terms of integrated solid waste collection's main characteristics. After that, some final thoughts are offered on how Addis Ababa can build an integrated solid waste collection facility based on the successful features implemented by Shanghai.

According to the statistical data of both countries (China and Ethiopia), the population of the two cities has a great difference. The population of Shanghai during the years of 2010, 2015, and 2019 was 20.31, 23.48, and 24.28 million respectively (Shanghai municipal statistics bureau 2020). However, the population of Addis Ababa was 3.13, 3.87, and 4.59 million in the same years (Central Statistics Agency of Ethiopia, 2019). In addition to this, the GDP per capita of the two cities has a large difference. The GDP per capita of Shanghai was 20,392 USD (Shanghai statistical yearbook 2018) whereas the GDP per capita of Addis Ababa was only 858 USD in the same year (Central statistical agency of Ethiopia 2019). Based on this information comparative analysis and discussion of the key features of solid waste collection practices of the two cities were undertaken as follows.

\subsection{Waste Generation}

As a country's economy develops, so does its per capita waste generation rate. GDP per capita, adjusted for buying power, is used to measure economic growth. As a country's population increases, so does the amount of total waste generated. On average, $1.02 \mathrm{~kg}$ per capita of household solid waste is generated in the city of 
Shanghai per day [51]. Addis Ababa's daily municipal solid waste generation average is $0.45 \mathrm{~kg}$ per capita. In 2018, the city of Shanghai handled a total of 26,000 tonnes of waste (Shanghai Bureau of Statistics, 2019), while Addis Ababa generates 2066 tonnes of waste per day [21]. In Addis Ababa, households are expected to produce the most waste (76 percent), followed by commercial and other institutions (9 percent), and hospitals with the lowest proportions (1 percent ). Every year, the municipality's waste generation rate is expected to rise by $5 \%$. The total waste amount generated and per capita waste generation in Addis Ababa are lower than those in Shanghai, according to the findings of this report. Since Shanghai's large population and economic growth (GDP per capita) may be the key factors causing this situation.

\subsection{Waste Composition}

The composition of domestic waste in the cities of Shanghai and Addis Ababa was depicted below (Table 2). The data for Addis Ababa's waste composition was limited to household waste; other non-residential waste treated by the city authority was not included. The waste composition available for Shanghai pertains to total municipal waste. Although the waste composition for Addis Ababa does not cover all waste sources, comparing it to the waste composition for Shanghai reveals a significant difference in waste composition.

The waste in Addis Ababa is mostly made up of biodegradable materials, with a significant amount of paper and cardboard thrown in for good measure. Organic waste and plastics dominate household waste in Shanghai and are present relatively in a large proportion. Shanghai also generates a higher percentage of paper and cardboard next to organic waste and plastic, which is recyclable. The disparities in waste composition can be traced back to the inhabitants of the two cities having different living conditions and lifestyles. Differences in waste composition can be seen in the quantity and types of natural resources available in the two cities' countries.

Table 2. Available waste composition data in Addis Ababa and Shanghai.

\begin{tabular}{ccc}
\hline Waste component & Shanghai $^{\mathrm{I}}(\%)$ & Addis Ababa $^{\mathrm{II}}(\%)$ \\
\hline Paper and cardboard & 9.57 & 13.5 \\
Plastic & 15.71 & 10.8 \\
Wood & 2.69 & 2.3 \\
Cloth/textile & 2.3 & 2.6 \\
Kitchen waste & 58.37 & 63 \\
Fruit and vegetables & 6.6 & 4.2 \\
Metal & 0.33 & ---- \\
Glasses & 2.53 & 1 \\
Stone & 0.53 & $-\cdots--$ \\
Hazardous waste & 0.05 & ---- \\
Others & 1.31 & 2.6 \\
\hline
\end{tabular}

Source: ${ }^{\mathrm{I}} \mathrm{MSW}$ composition in Shanghai [52]. ${ }^{\mathrm{II}}$ Field survey (September 2020). 


\subsection{Waste Collection Methods, Service Coverage, and Separation Practice}

Shanghai's municipal waste management facilities are available to all city residents. Residents of the city have been given instructions on how to manage the different forms of waste created in order to ensure that all waste generated in the city is collected. Municipal solid waste is divided into four groups in Shanghai: recyclable, dangerous, wet, and dry waste. Hazardous, recyclable, wet, and dry waste should be placed in the red, blue, brown, and black bins, respectively [53]. First, people are expected to categorize waste and then throw it into the correct bins. It will not collect unclassified waste. Besides, people are expected to throw waste at designated locations and times. No waste collection outside of the time slots and places specified is allowed. About 31,319 units of solid waste collection points and 80,360 units of trash cans are available in Shanghai [54]. The waste will then be collected by eligible businesses and transported to various locations for proper disposal. Recycling businesses can recycle recyclable waste in order to maximize resource usage. Hazardous waste will be transported to waste treatment plants where it will be treated with high-temperature, chemical, and other treatment methods to render it harmless. After complex chemical and biological treatments in waste treatment plants, the wet waste can be used to generate biogas or used as a natural fertilizer. Dry waste can be incinerated to produce energy in waste incineration plants or discarded in landfills. Different kinds of waste will be transported by various forms of waste vehicles. To collect and move waste on time, tens of thousands of waste vehicles have been arranged.

For the entire waste throwing, processing, transportation, and disposal process, laws and regulations have been implemented. Those who fail to properly classify and/or throw waste, for example, will be fined CNY 50 to CNY 200, and waste conveyance enterprises that mix the categorized waste will be punished CNY 5000 to CNY 50,000, as per the Shanghai Municipal Solid Waste Management Legislation [53].

In the case of Addis Ababa, two types of methods are employed for the collection of municipal solid waste in the city. Primary and secondary collection system. Micro and small enterprises with formal agreements to collect from houses and dump them in specified containers conduct the primary collection. They use a door-to-door method to gather and dumped in an alternative container to be picked by secondary collectors, the sub-city, and private firms, and then dumped it at the city's landfill. These are the house-to-house (curbside) solid waste collection utilizing a hand pushcart and communal solid waste collection.

The secondary collection is a system of transferring garbage from the containers to the last discarding site, undertaken by the municipality, which signifies the maximum level in the transportation system. The communal collection method includes the placing of metal containers (skips) at designated sites known as transfer stations, shared within that group by many buildings. When the skips are full, the skip loading trucks are transported and thoroughly cleaned at the 
final disposal site. Container services also rely on collecting waste from institutional and industrial premises. From the total of the waste generated only $70 \%$ is collected in the municipality.

According to the finding of this research, the comparison of solid waste collection and separation rate of both cities have been shown below (Figure 5).

The role of the private sector in this system is limited other than informal collectors of recyclable wastes. It is well prepared for Addis Ababa's regulations and laws. However, there is a significant difference between what is written in the articles and what is actually done. There has been no substantial improvement in the ten years since any of the proclamations were issued. In addition, the rules are mostly non-practical. The effort required to put the regulations into effect has somehow been overlooked. Despite the fact that all of the regulations are good in theory, only a few of them are implemented by the city administration and citizens, and little enforcement is done. Many residents find it difficult to comply with the regulations since they lack access to a proper solid waste system that helps them to manage their waste in accordance with the rules. The Comparison of GDP per capita, waste generation per capita, solid waste separation, and collection rate of Shanghai and Addis Ababa were depicted below (Table 3).

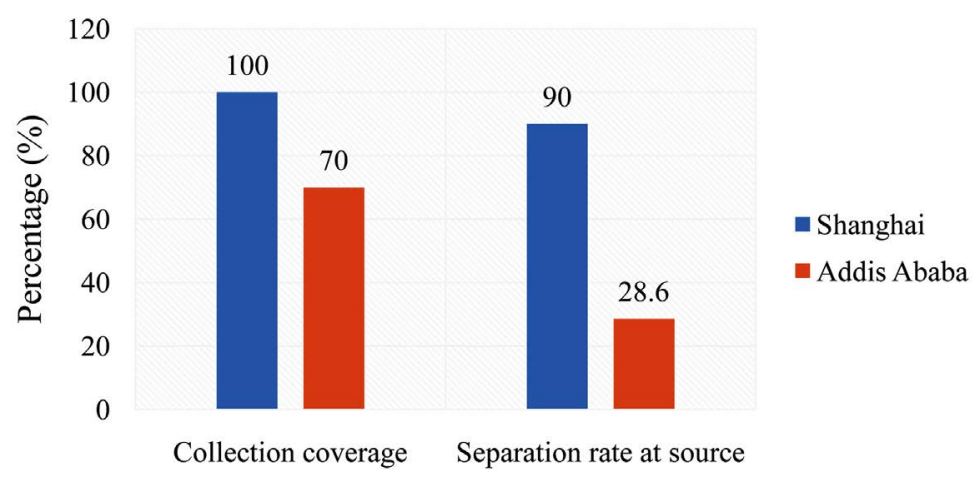

Figure 5. Solid waste collection and separation rate of Shanghai and Addis Ababa.

Table 3. Comparison of GDP per capita, waste generation per capita, solid waste separation, and collection rate of Shanghai and Addis Ababa.

\begin{tabular}{ccc}
\hline Indicators & Shanghai $^{\mathrm{I}}$ & Addis Ababa $^{\mathrm{II}}$ \\
\hline $\begin{array}{c}\text { GDP per capita } \\
\text { Solid waste generation } \\
\text { per capita per day }\end{array}$ & $\$ 20,392($ As 2018) & $\$ 858$ (As 2018) \\
Total solid waste generation \\
per year in the city \\
$\begin{array}{c}\text { Solid waste separation } \\
\text { coverage in the city }\end{array}$ & 9 million tons & $0.45 \mathrm{~kg} / \mathrm{day}$ \\
$\begin{array}{c}\text { Solid waste treatment } \\
\text { coverage in the city }\end{array}$ & $90 \%$ & 754,236 tons \\
\end{tabular}

Source: ${ }^{\mathrm{I}}[55]$, ${ }^{\mathrm{II}}$ Field survey (September 2020). 


\subsection{Control and Handling of All Wastes Generated}

In 2018, Shanghai handled a total of 9 million tonnes of waste, compared to 754,236 tonnes produced in Addis Ababa, which has a per capita waste generation of $0.45 \mathrm{~kg} /$ day and a population density of 8148 people per $\mathrm{km}^{2}$. This comparison indicates that, despite having a lower per capita waste generation rate and a lower overall amount of waste to handle than Shanghai, Addis Ababa's collection coverage is extremely poor. This suggests that the amount of waste handled in a developing country's urban area is less than that handled in a developed country's urban area; therefore, integrated waste management systems in both urban settings are urgently needed. The city of Shanghai uses a variety of collection and treatment methods to ensure that all waste produced in the city is accounted for, while more than $30 \%$ of waste generated in Addis Ababa is not collected or accounted for. Furthermore, Shanghai's solid waste separation practice is exemplary even for other Chinese cities, whereas Addis Ababa's performance is insignificant. The two waste collection systems in Addis Ababa could be carefully evaluated and optimized for different parts of the city to ensure that all waste generated is accounted for. The city of Shanghai's waste and resource material collection bylaw holds the municipal government and people responsible for the disposal of all waste produced in the city [53]. This means that the city's waste is under control. Addis Ababa's waste management bylaw needs to be updated. The responsibilities of residents and local governments should be defined in the revised bylaw, with stringent and consistent penalties that promote enforcement, as seen in the City of Shanghai's waste management bylaws.

Lastly, based on the best practices of Shanghai, the solid waste collection system of Addis Ababa city might be redesigned as discussed below (Figure 6).

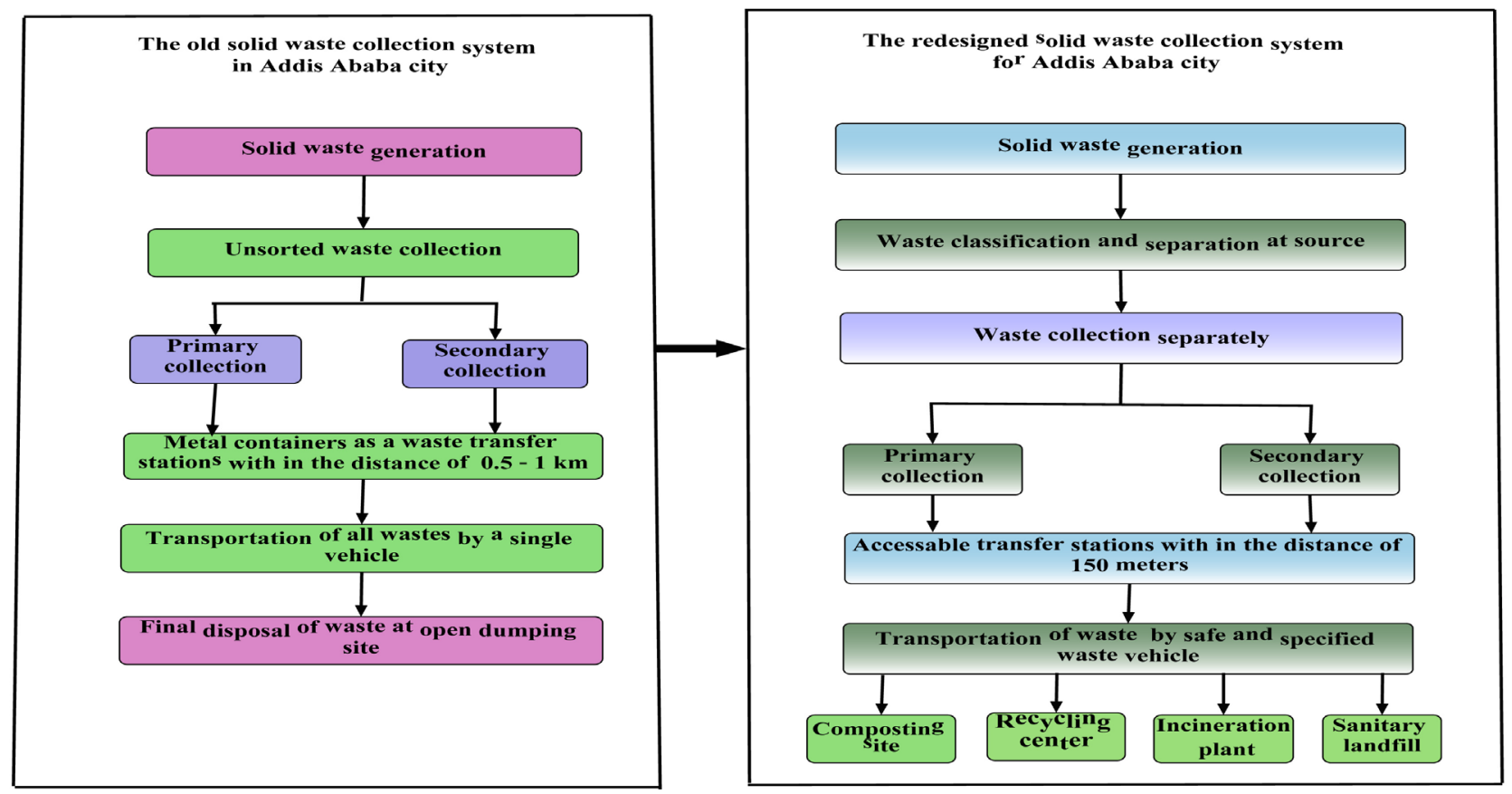

Figure 6. The previous solid waste collection system and the redesigned one for Addis Ababa. 
According to this design, there are fundamental differences between the new and the old solid waste collection system. The first difference is the classification of solid waste according to its nature and the need for separation at source. The second difference is the collection and loading system. In the old system, all the garbage was unsorted and transported by a single truck. However, with the new design, all types of waste are collected separately from the source and then transported by different, safe, and specific waste trucks. The third difference is the accessibility of waste collection containers. In the old system, its distance from the household is $0.5-1 \mathrm{~km}$, whereas $150 \mathrm{~m}$ distance is proposed in the new one. The other difference is the final disposal system. Under the old system, the entire city's waste was taken to an open garbage dumpsite. In the new design, however, the wastes will be taken to different treatment facilities. Accordingly, the solid waste collection and transference system of Addis Ababa city will be improved.

\section{Conclusions}

This paper has tried to explore the status and spatial coverage of municipal solid waste collection provision of Addis Ababa city and then a comparative analysis with Shanghai's has been undertaken in general. According to the finding of this study, the solid waste collection performance of Addis Ababa city is very low when compared with Shanghai. Especially solid waste segregation at source is insignificant. The research examined into the rate at which households generate solid waste, how they collect it, and the factors that influence the city's solid waste collection service.

The city of Shanghai's waste collection system has made significant progress in recent years, owing to the city's belief that a sustainable waste collection service is founded on strong guiding principles, good service delivery standards, as many local solutions as possible, and running at a fiscally responsible rate. This attitude is needed to drive waste collection in Addis Ababa, as well as the majority of developing countries, towards higher levels of sustainability. Any significant improvement in Addis Ababa's MSW set would necessitate close collaboration between the government, the private sector, and people. The resources and characteristics available for municipal solid waste collection in Shanghai and Addis Ababa are different as elaborated in the municipal solid waste collection overview. The following are some of the lessons that can be learned from Shanghai's collection system in order to boost municipal solid waste collection in Addis Ababa:

Preparing a city-wide strategic, coordinated solid waste collection plan and design. The plan should be created with the city's socioeconomic and cultural framework in mind, as well as the waste generation sources, quantity, and characteristics. All potential stakeholders in the waste collection system must be listed and brought together when designing the proposal. To ensure that stakeholders feel like they are a part of and committed to the waste handling 
system's efficiency, all stakeholders should agree on the target and performance metrics and communicate them properly to all parties.

* Intensive education of the city's residents is needed to ensure that they fully understand the health risks raised by inadequate MSWM, which will motivate them to pay attention to MSWM services.

* The government's rules and regulations should be in line with the realities of the city. There is also a need for thorough study in order to develop a plan for implementing laws, legislation, and declarations, as well as how to instill values in society. To ensure that there are no grounds for noncompliance, these bylaws should be made available (communicated sufficiently) to the city's residents.

\section{Acknowledgements}

The writers are very thankful for the useful comments and suggestions made by colleagues at Tongji University as well as for the encouragement and support of the Institute of Environment for Sustainable Development (IESD). We would like also to express our sincere gratitude to Mr. Amare Beka, Mr. Aklilu Teshome, and Mr. Mikias Teshome for their tireless support during the data collection of this research.

\section{Conflicts of Interest}

The authors announced that there were no conflicting interests.

\section{Declaration of Funding}

This research was supported by the commerce ministry scholarship of the people's republic of China through a study scholarship for Diriba Dechasa Beka. The authors are thankful to the commerce ministry scholarship of the people's republic of China for financially supporting.

\section{Authors' Contributions}

The manuscript was designed, prepared, and revised by both authors as well as the final manuscript was read and accepted.

\section{References}

[1] Joshi, R. and Ahmed, S. (2016) Status and Challenges of Municipal Solid Waste Management in India: A Review. Cogent Environmental Science, 2, Article ID: 1139434. https://doi.org/10.1080/23311843.2016.1139434

[2] Marshall, R.E. and Farahbakhsh, K. (2013) Systems Approaches to Integrated Solid Waste Management in Developing Countries. Waste Management, 33, 988-1003. https://doi.org/10.1016/j.wasman.2012.12.023

[3] Zheng, H., Kou, K.P. and Ge, Y. (2017) Environmental Risk Assessment of the Municipal Solid Waste in a City-State: A Case Study of Macao. Human and Ecological Risk Assessment: An International Journal, 23, 1796-1818.

https://doi.org/10.1080/10807039.2017.1346463 
[4] Chinasho, A. (2015) Review on Community Based Municipal Solid Waste Management and Its Implication for Climate Change Mitigation. American Journal of Scientific and Industrial Research, 6, 41-46.

[5] Singh, G.K., Gupta, K. and Chaudhary, S. (2014) Solid Waste Management: Its Sources, Collection, Transportation and Recycling. International Journal of Environmental Science and Development, 5, 347. https://doi.org/10.7763/IJESD.2014.V5.507

[6] Wilson, D., et al. (2015) Global Waste Management Outlook; Prepared for United Nations Environment Programme (UNEP) and International Solid Waste Association (ISWA). UNEP International Environment Technology Centre (IETC), Osaka.

[7] Cheru, M. (2016) Solid Waste Management in Addis Ababa: A New Approach to Improving the Waste Management System.

[8] Khajuria, A., Yamamoto, Y. and Morioka, T. (2010) Estimation of Municipal Solid Waste Generation and Landfill Area in Asian Developing Countries. Journal of Environmental Biology, 31, 649-654.

[9] Shukla, G., Shashi, M. and Jain, K. (2012) Decision Support System for Selecting Suitable Site for Disposing Solid Waste of Township. International Journal of Remote Sensing and GIS, 1, 2-11.

[10] Zuberi, M.J.S. and Ali, S.F. (2015) Greenhouse Effect Reduction by Recovering Energy from Waste Landfills in Pakistan. Renewable and Sustainable Energy Reviews, 44, 117-131. https://doi.org/10.1016/j.rser.2014.12.028

[11] Parizeau, K., Maclaren, V. and Chanthy, L. (2006) Waste Characterization as an Element of Waste Management Planning: Lessons Learned from a Study in Siem Reap, Cambodia. Resources, Conservation and Recycling, 49, 110-128. https://doi.org/10.1016/j.resconrec.2006.03.006

[12] U.N.H.S. (2010) Programme, Solid Waste Management in the World's Cities: Water and Sanitation in the World's Cities. Earthscan.

[13] Lohri, C.R., Camenzind, E.J. and Zurbrügg, C. (2014) Financial Sustainability in Municipal Solid Waste Management-Costs and Revenues in Bahir Dar, Ethiopia. Waste Management, 34, 542-552. https://doi.org/10.1016/j.wasman.2013.10.014

[14] Memon, M.A. (2010) Integrated Solid Waste Management Based on the 3R Approach. Journal of Material Cycles and Waste Management, 12, 30-40. https://doi.org/10.1007/s10163-009-0274-0

[15] Shekdar, A.V. (2009) Sustainable Solid Waste Management: An Integrated Approach for Asian Countries. Waste Management, 29, 1438-1448.

https://doi.org/10.1016/j.wasman.2008.08.025

[16] Massoud, M.A. and El-Fadel, M. (2002) Public-Private Partnerships for Solid Waste Management Services. Environmental Management, 30, 621-630. https://doi.org/10.1007/s00267-002-2715-6

[17] Kruljac, S. (2012) Public-Private Partnerships in Solid Waste Management: Sustainable Development Strategies for Brazil. Bulletin of Latin American Research, 31, no. 2, 222-236. https://doi.org/10.1111/j.1470-9856.2011.00659.x

[18] Qdais, H.A. (2007) Techno-Economic Assessment of Municipal Solid Waste Management in Jordan. Waste Management, 27, 1666-1672.

https://doi.org/10.1016/j.wasman.2006.08.004

[19] Rathi, S. (2007) Optimization Model for Integrated Municipal Solid Waste Management in Mumbai, India. Environment and Development Economics, 12, 105 121. https://doi.org/10.1017/S1355770X0600341X

[20] Fesseha, S.N. and Bin, F. (2015) The Assessment of Solid Waste Products Manage- 
ment in Ethiopians Municipal Urban Areas. International Journal of Social Sciences and Management, 2, 165-179. https://doi.org/10.3126/ijssm.v2i2.12468

[21] Mohammed, A. and Elias, E. (2017) Domestic Solid Waste Management and Its Environmental Impacts in Addis Ababa City. Journal of Environment and Waste management, 4, 194-203.

[22] Dolamo, B. and Desalegn, T. (2016) Public Awareness of Existing Environmental Health Regulations and Their Application in Urban and Peri-Urban of Addis Ababa, Ethiopia. Africa Journal of Nursing and Midwifery, 18, 142-156. https://doi.org/10.25159/2520-5293/413

[23] Kabite, G., Suryabhagavan, K., Argaw, M. and Sulaiman, H. (2012) GIS-Based Solid Waste Landfill Site Selection in Addis Ababa, Ethiopia. International Journal of Ecology and Environmental Sciences, 38, 59-72.

[24] Thongyuan, S., Khantamoon, T., Aendo, P., Binot, A. and Tulayakul, P. (2021) Ecological and Health Risk Assessment, Carcinogenic and Non-Carcinogenic Effects of Heavy Metals Contamination in the Soil from Municipal Solid Waste Landfill in Central, Thailand. Human and Ecological Risk Assessment. An International Journal, 27, 876-897. https://doi.org/10.1080/10807039.2020.1786666

[25] Regassa, N., Sundaraa, R.D. and Seboka, B.B. (2011) Challenges and Opportunities in Municipal Solid Waste Management: The Case of Addis Ababa City, Central Ethiopia. Journal of Human Ecology, 33, 179-190. https://doi.org/10.1080/09709274.2011.11906358

[26] Zarate, M., Slotnick, J. and Ramos, M. (2008) Capacity Building in Rural Guatemala by Implementing a Solid Waste Management Program. Waste Management, 28, 2542-2551. https://doi.org/10.1016/j.wasman.2007.10.016

[27] Ezeah, C. and Roberts, C.L. (2012) Analysis of Barriers and Success Factors Affecting the Adoption of Sustainable Management of Municipal Solid Waste in Nigeria. Journal of Environmental Management, 103, 9-14. https://doi.org/10.1016/j.jenvman.2012.02.027

[28] Kasa, L., Zeleke, G., Alemu, D., Hagos, F. and Heinimann, A. (2011) Impact of Urbanization of Addis Ababa City on Peri-Urban Environment and Livelihoods. Sekota Dry Land Agricultural Research Centre of Amhara Regional Agricultural Research Institute, Addis Ababa.

[29] Mazloomi, S., Madani, V., Hosseini, M., Majlessi, M. and Amarlooei, A. (2015) Analyzing Costs of Collection and Transportation of Municipal Solid Waste Using WAGs and Arc GIS: A Case Study in Tabriz, Iran. Journal of Advances in Environmental Health Research, 3, 258-265.

[30] Srivastava, V., Ismail, S.A., Singh, P. and Singh, R.P. (2015) Urban Solid Waste Management in the Developing World with Emphasis on India: Challenges and Opportunities. Reviews in Environmental Science and Biol Technology, 14, 317-337. https://doi.org/10.1007/s11157-014-9352-4

[31] Erami, S., Pashaei, T. and Shahmoradi, B. (2015) Developing a Questionnaire on Strategies for Increasing Housewives' Participation in Source Separation of Municipal Solid Waste Based on the Theory of Planned Behavior. Journal of Advances in Environmental Health Research, 3, 1-7.

[32] Abebe, M.A. (2018) Challenges and Practice of Plastic Bottles, Paper and Carton Generation and Collection in Addis Ababa City, Ethiopia. European Journal of Research, No. 5-6, 117-132.

[33] Miezah, K., Obiri-Danso, K., Kádár, Z., Fei-Baffoe, B. and Mensah, M.Y. (2015) Municipal Solid Waste Characterization and Quantification as a Measure towards 
Effective Waste Management in Ghana. Waste Management, 46, 15-27. https://doi.org/10.1016/j.wasman.2015.09.009

[34] Tassie, K., Endalew, B. and Mulugeta, A. (2019) Composition, Generation and Management Method of Municipal Solid Waste in Addis Ababa City, Central Ethiopia: A Review. Asian Journal of Environment \& Ecology, 9, 1-19. https://doi.org/10.9734/ajee/2019/v9i230088

[35] Getahun, T., et al. (2012) Municipal Solid Waste Generation in Growing Urban Areas in Africa: Current Practices and Relation to Socioeconomic Factors in Jimma, Ethiopia. Environmental Monitoring and Assessment, 184, 6337-6345. https://doi.org/10.1007/s10661-011-2423-x

[36] Tessema, M. (2010) Overview of Addis Ababa City Solid Waste Management System. Division for Sustainable Development, Department of Economic and Social Affairs, United Nations, Addis Ababa.

[37] Teweldemedhin, M., Gebreyesus, H., Atsbaha, A.H., Asgedom, S.W. and Saravanan, M. (2017) Bacterial Profile of Ocular Infections: A Systematic Review. BMC Ophthalmology, 17, 212. https://doi.org/10.1186/s12886-017-0612-2

[38] Zerbock, O. (2003) Urban Solid Waste Management: Waste Reduction in Developing Nations. Written for the Requirements of CE, 5993.

[39] Gyimah, P. (2018) Households' Solid Waste Separation Practices in the Cape Coast Metropolitan Area. University of Cape Coast, Cape Coast. https://doi.org/10.1007/s10708-019-10084-4

[40] Zemena, G. (2016) Solid Waste Management Practice and Factors Influencing Its Effectiveness: The Case of Selected Private Waste Collecting Companies in Addis Ababa. St. Mary's University, San Antonio.

[41] Kibrekidusan, S. (2017) Assessment of Practices, Challenges, and Prospects of InHouse Solid Waste Management in Addis Ababa: The Case of Yeka Sub-City.

[42] Amiga, A. (2002) Households' Willingness to Pay for Improved Solid Waste Management: The Case of Addis Ababa. A Thesis of Master of Science in Economics (Human Resource Economics), The School of Graduates Studies of Addis Ababa University, Addis Ababa.

[43] Tilaye, M. and Van Dijk, M.P. (2014) Private Sector Participation in Solid Waste Collection in Addis Ababa (Ethiopia) by Involving Micro-Enterprises. Waste Management \& Research, 32, 79-87. https://doi.org/10.1177/0734242X13513826

[44] Henry, R.K., et al. (2006) Municipal Solid Waste Management Challenges in Developing Countries-Kenyan Case Study. Waste Management, 26, 92-100. https://doi.org/10.1016/j.wasman.2005.03.007

[45] Ngoc, U.N. and Schnitzer, H. (2009) Sustainable Solutions for Solid Waste Management in Southeast Asian Countries. Waste Management, 29, 1982-1995. https://doi.org/10.1016/j.wasman.2008.08.031

[46] Ogunbode, C.A. and Arnold, K. (2012) A Study of Environmental Awareness and Attitudes in Ibadan, Nigeria. Human and Ecological Risk Assessment. An International Journal, 18, 669-684. https://doi.org/10.1080/10807039.2012.672901

[47] Dika, G., Nemie, A. and Birhane, E. (2019) Household's Willingness to Pay for Improved Solid Waste Management in Gulelle Sub City, Addis Ababa. Energy and Environmental Engineering, 6, 1-7. https://doi.org/10.13189/eee.2019.060101

[48] Gadallah, W.B.H. (2016) Impact of Waste on Environment in Ombada Locality, Khartoum State, Sudan. Sudan University of Science \& Technology, Khartoum.

[49] Kuma, T. (2004) Dry Waste Management in Addis Ababa City. Teaching Work- 
shop, Addis Ababa, 5-16 January 2004, 1-12.

[50] Debere, M.K., Gelaye, K.A., Alamdo, A.G. and Trifa, Z.M. (2013) Assessment of the Health Care Waste Generation Rates and Its Management System in Hospitals of Addis Ababa, Ethiopia, 2011. BMC Public Health, 13, Article No. 28. https://doi.org/10.1186/1471-2458-13-28

[51] Lu, H. and Sidortsov, R. (2019) Sorting Out a Problem: A Co-Production Approach to Household Waste Management in Shanghai, China. Waste Management, 95, 271-277. https://doi.org/10.1016/j.wasman.2019.06.020

[52] Dai, S. (2016) Optimized WtE Conversion of Municipal Solid Waste in Shanghai Applying Thermochemical Technologies.

[53] Zhou, M.-H., Shen, S.-L., Xu, Y.-S. and Zhou, A.-N. (2019) New Policy and Implementation of Municipal Solid Waste Classification in Shanghai, China. International Journal of Environmental Research and Public Health, 16, 3099. https://doi.org/10.3390/ijerph16173099

[54] Pan, H., Zhuang, M., Geng, Y., Wu, F. and Dong, H. (2019) Emergy-Based Ecological Footprint Analysis for a Mega-City: The Dynamic Changes of Shanghai. Journal of Cleaner Production, 210, 552-562. https://doi.org/10.1016/j.jclepro.2018.11.064

[55] Xiao, S., Dong, H., Geng, Y., Tian, X., Liu, C. and Li, H. (2020) Policy Impacts on Municipal Solid Waste Management in Shanghai: A System Dynamics Model Analysis. Journal of Cleaner Production, 262, Article ID: 121366.

https://doi.org/10.1016/j.jclepro.2020.121366 